Surgery for

Congenital

Heart Disease

\title{
Does a bidirectional Glenn shunt improve the oxygenation of right ventricle-dependent coronary circulation in pulmonary atresia with intact ventricular septum?
}

Kagami Miyaji, MD, ${ }^{a}$ Arata Murakami, MD, ${ }^{\text {b }}$ Tai-ichi Takasaki, MD, ${ }^{a}$ Kuniyoshi Ohara, MD, ${ }^{a}$ Shinichi Takamoto, MD, ${ }^{\mathrm{b}}$ and Hirokuni Yoshimura, $\mathrm{MD}^{\mathrm{a}}$

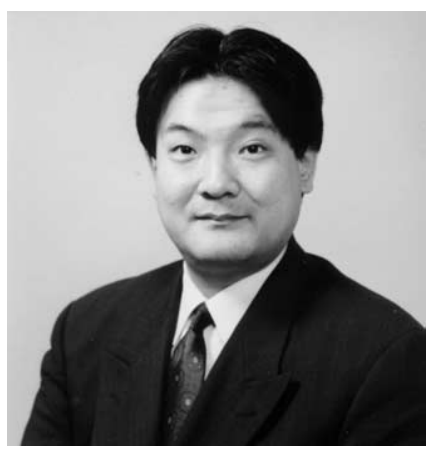

Dr Miyaji
From the Department of Thoracic and Cardiovascular Surgery, Kitasato University School of Medicine Kitasato, Sagamihara, Japan, ${ }^{\mathrm{a}}$ and the Department of Cardiac Surgery, University of Tokyo Hospital, Hongo, Bunkyo-ku, Tokyo, Japan. ${ }^{\text {b }}$

Received for publication Dec 23, 2004; revisions received April 19, 2005; accepted for publication April 27, 2005.

Address for reprints: Kagami Miyaji, MD, Department of Thoracic and Cardiovascular Surgery, Kitasato University, School of Medicine, Kitasato 1-15-1, Sagamihara, 228-8555 Japan (E-mail: kagami111@aol.com)

J Thorac Cardiovasc Surg 2005;130:1050-3 $0022-5223 / \$ 30.00$

Copyright (C) 2005 by The American Association for Thoracic Surgery

doi:10.1016/j.jtcvs.2005.04.026
Objective: There is a risk of myocardial ischemia in patients with pulmonary atresia and intact ventricular septum associated with the right ventricle-dependent coronary circulation. In this patient group, the oxygen delivery to the myocardium depends on the oxygen saturation of the right ventricular cavity. We hypothesized that bidirectional Glenn shunt would improve the oxygenation of right ventricledependent coronary circulation relative to a systemic-pulmonary artery shunt. The reduction of systemic venous return to the right atrium due to a bidirectional Glenn shunt could increase the oxygen saturation of the right ventricle in the clinical setting, when the mixture of systemic and pulmonary venous blood is unchanged at the atrial level.

Methods: Patients with right ventricle-dependent coronary circulation were defined as those with right ventricle-coronary artery fistulas plus stenoses of the right or left coronary arteries. For 7 patients with right ventricle-dependent coronary circulation before and after bidirectional Glenn shunt, cardiac catheterization was performed and the oxygen saturation of the right ventricular cavity was measured.

Results: For all 7 patients, the bidirectional Glenn shunt was performed at a mean age of 18 months. Ischemic changes in the electrocardiogram before the bidirectional Glenn shunt improved after the procedure in 2 patients. The oxygen saturation of the right ventricular cavity before the bidirectional Glenn shunt was $54.6 \pm 8.8 \%$, and that after the BGS significantly increased to $75.6 \% \pm 5.8 \%(P<.01)$. All 7 patients have subsequently undergone the Fontan procedure with excellent results.

Conclusion: Early bidirectional Glenn shunt could prevent progression of myocardial ischemia in pulmonary atresia with intact ventricular septum with right ventricledependent coronary circulation.

$\mathrm{T}$ he outcome of pulmonary atresia with intact ventricular septum (PA/IVS) has been poor in many previously reported studies. ${ }^{1-3}$ A recent study, however, reported an improved survival of $98 \%$ at 7 years. ${ }^{4}$ The morphologic heterogeneity in PA/IVS encompasses a spectrum of lesions, including hypoplasia of the right ventricle (RV) and the tricuspid valve, abnormal coronary circulation, and pulmonary atresia itself. ${ }^{5}$ If all measures are favorable, a biven- 
TABLE 1. Patient data

\begin{tabular}{|c|c|c|c|c|c|c|}
\hline No. & Sinusoid pattern & Coronary stenosis & Previous palliation & $\begin{array}{l}\text { Ischemic change in } \\
\text { ECG before BGS }\end{array}$ & $\begin{array}{l}\text { Ischemic change } \\
\text { in ECG after BGS }\end{array}$ & Outcome \\
\hline 1 & LCA & LAD interruption & Right MBTS & + & - & TCPC, surviving \\
\hline 2 & LCA & - & Right MBTS & - & - & TCPC, surviving \\
\hline 3 & LCA, RCA & LAD stenosis & Right MBTS & - & - & TCPC, surviving \\
\hline 4 & RCA, LAD & RCA stenosis & - & - & - & TCPC, surviving \\
\hline 5 & RCA, LAD & LAD stenosis & Right MBTS & + & - & TCPC, surviving \\
\hline 6 & LCA, RCA & LCA stenosis & Right MBTS & - & - & TCPC, surviving \\
\hline 7 & LAD & LCA stenosis & Right MBTS & - & - & TCPC, surviving \\
\hline
\end{tabular}

$E C G$, Electrocardiogram; $B G S$, bilateral Glenn shunt; $L C A$, left coronary artery; $L A D$, left anterior descending branch; MBTS, modified Blalock-Taussig shunt; $T C P C$, total cavopulmonary connection; $R C A$, right coronary artery.

tricular repair will be achieved; if not, a Fontan procedure or a one-and-a-half ventricle repair will be done. ${ }^{6}$

There is a risk of myocardial ischemia in patients with $\mathrm{RV}$-dependent coronary circulation. In this group of patients, the oxygen delivery to the myocardium depends on the oxygen saturation $\left(\mathrm{SO}_{2}\right)$ of the RV cavity. We hypothesized that a bidirectional Glenn shunt (BGS) would improve the oxygenation of RV-dependent coronary circulation relative to a systemic-pulmonary artery shunt. The reduction of systemic venous return to the right atrium after a BGS could increase the $\mathrm{So}_{2}$ of the $\mathrm{RV}$ in the clinical setting, when the mixture of systemic and pulmonary venous blood is unchanged at the atrial level. Here, we review cardiac catheterization data from patients with RV-dependent coronary circulation.

\section{Methods}

Between 1998 and 2001, a total of 7 patients with PA/IVS, severe hypoplastic RV, and sinusoidal communication underwent the BGS procedure. Patients with RV-dependent coronary circulation were those with RV-coronary artery fistulas plus stenoses of the right or left coronary arteries. Six patients had RV-dependent coronary circulation, and 4 had a stenotic lesion in the left coronary artery or the left anterior descending branch, 1 had an interruption of left anterior descending branch, and another had a stenotic lesion in the right coronary artery (Table 1). Another patient had no stenosis on the coronary artery; however, the aim of this study was to clarify the effect of BGS on the $\mathrm{SO}_{2}$ of the RV cavity, and the hemodynamics of sinusoidal communications with and without major coronary stenoses are quite similar.

Informed consents for both the operation and cardiac catheterization were obtained from the parents of all children. Data collection was performed according to the guidelines of the institutional review board.

\section{Surgical Intervention}

For 6 patients, a modified Blalock-Taussig shunt (MBTS) was performed on the right side through a median sternotomy. Another patient had a stable patent ductus arteriosus, and no procedure was needed before BGS. The mean age at MBTS was 4.7 months (range 21 days to 22 months). A $3.5-\mathrm{mm}$ polytetrafluoroethylene tube graft was used to construct the shunt in all patients, with the proximal anastomosis being placed at the innominate artery. The subsequent intervention was BGS in all cases. Two patients also had an enlargement of an atrial septal defect. The mean age at BGS was 18 months (range 11-27 months). The interval between MBTS and BGS was 16.5 months (range 9.5-27 months).

\section{Cardiac Catheterization}

Cardiac catheterization was performed in all 7 patients before and after BGS. The mean interval before BGS was 5.5 months and that after BGS was 11.3 months. All patients underwent aortography and right ventriculography. The coronary artery-RV fistulas, coronary sinusoids, and coronary stenoses were identified. We defined $\mathrm{RV}$-dependent coronary circulation as RV-coronary artery fistulas plus stenoses (more than 50\%) of the right or left coronary arteries.

The blood samples were collected from the superior vena cava, inferior vena cava (IVC), right atrium, RV cavity, pulmonary artery, and aorta. The ratio of pulmonary to systemic blood flow was calculated. The $\mathrm{SO}_{2}$ of the RV cavity and that of mixed venous blood flow into the right atrium were compared before and after the BGS. The mixed $\mathrm{VO}_{2}$ before $\mathrm{BGS}$ was obtained from the following equation ${ }^{7}$ : mixed $\mathrm{VO}_{2}=\left[\left(\right.\right.$ superior vena cava $\left.\mathrm{So}_{2} \times 3\right)$ + IVC $\left.\mathrm{SO}_{2}\right] / 4$. And after BGS, mixed $\mathrm{Vo}_{2}$ was defined as the $\mathrm{So}_{2}$ of the IVC. In patients with $\mathrm{RV}$-dependent coronary circulation, the oxygen delivery to the myocardium partly depends on the $\mathrm{SO}_{2}$ of the RV cavity.

\section{Statistical Analysis}

All results are reported as mean \pm SD. The 2-tailed paired Student $t$ test was used for comparisons between values before and after the BGS.

\section{Results}

Before the BGS, the ratio of pulmonary to systemic blood flow was $1.34 \pm 0.6$ (range 0.46-2.2), and the $\mathrm{So}_{2}$ of the aorta was $74.0 \% \pm 6.9 \%$ (range $38.7 \%-60.9 \%$ ). After the BGS, the ratio of pulmonary to systemic blood flow was significantly decreased to $0.66 \pm 0.18$ (range $0.47-1.0, P<$ $.05)$. The $\mathrm{So}_{2}$ was significantly increased to $87.1 \% \pm 3.1 \%$ (range $83.5 \%-92.8 \%, P<.01$ ). The $\mathrm{So}_{2}$ of the RV cavity before the BGS was $54.6 \% \pm 8.8 \%$, and that after the BGS 


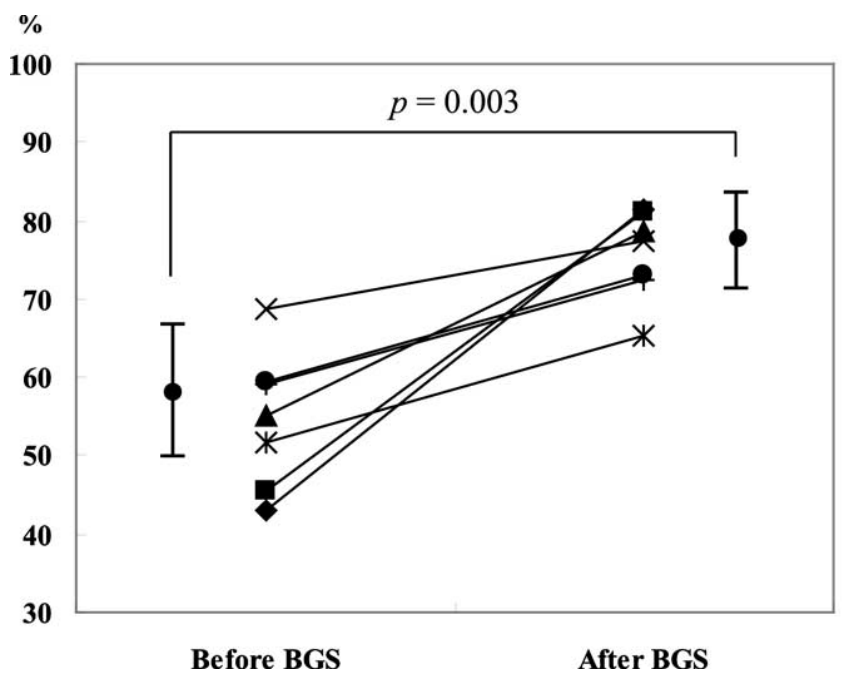

Figure 1. $\mathrm{SO}_{2}$ of $\mathrm{RV}$ cavity was increased after $\mathrm{BGS}$ in all cases.

was increased significantly to $75.6 \% \pm 5.8 \%(P<.01$; Figure 1). The mixed $\mathrm{VO}_{2}$ before the BGS was $50.8 \% \pm$ $8.1 \%$, and the $\mathrm{So}_{2}$ of the IVC after the BGS was significantly increased to $67.5 \% \pm 5.0 \%(P<.01$; Figure 2$)$. These results suggest that the BGS procedure improved the oxygen delivery to the myocardium in the RV-dependent coronary circulation. In fact, ischemic changes in the electrocardiogram before the BGS improved after the BGS in 2 patients (Table 1). One patient had a bigeminal premature ventricular contraction before BGS. After BGS, there were no premature ventricular contractions on electrocardiography. Another patient had ST depressions on leads $\mathrm{V}_{5}$ through $\mathrm{V}_{6}$ before BGS. The ST changes improved, and left ventricular (LV) function (LV ejection fraction) increased from 0.52 to 0.68 after BGS. All 7 patients have subsequently undergone the Fontan procedure with excellent results.

\section{Discussion}

PA/IVS is an anatomically heterogeneous congenital heart disease that shows morphologic variations in the size of the tricuspid annulus, the size of the RV cavity, and coronary artery anomalies, in association with RVdependent coronary circulation. ${ }^{8,9}$ Giglia and colleagues ${ }^{10}$ demonstrated that RV decompression is contraindicated in the presence of stenosis or occlusion of the coronary arteries. Death in patients with RV-dependent coronary circulation who undergo RV decompression is most probably related to the amount of the LV myocardium at risk for ischemia. Thus patients with markedly hypoplastic tricuspid valves and RVs or with $\mathrm{RV}$-dependent coronary circulation are not candidates for biventricular repair. ${ }^{11,12}$ In previous reports ${ }^{4}$ there has been a direct correlation between the size of the RV and

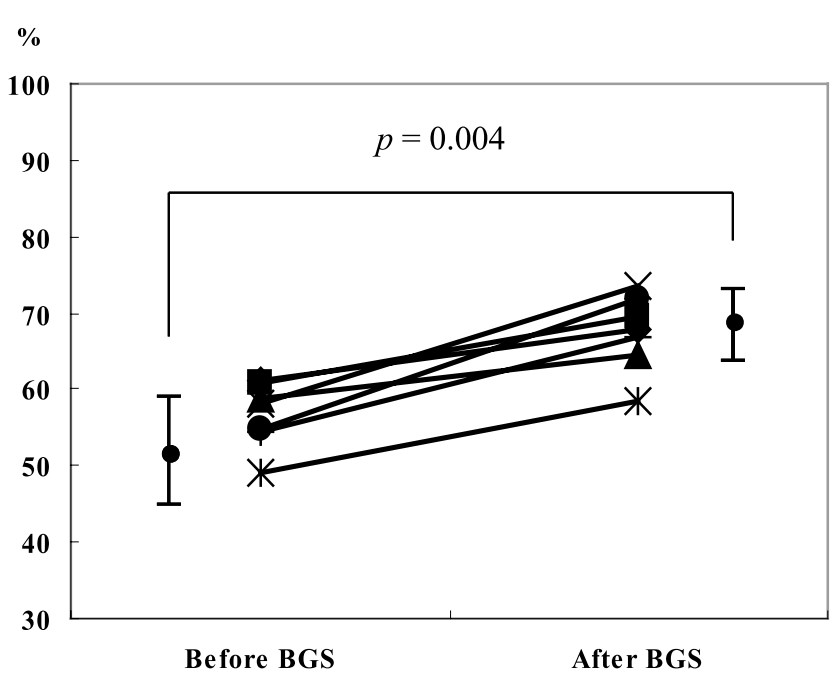

Figure 2. Mixed $\mathrm{V}_{2}$ was increased after $\mathrm{BGS}$ in all cases.

the tricuspid valve and the presence of RV-dependent coronary circulation. Patients with RV-dependent coronary circulations tend to have smaller RVs and tricuspid valves.

$\mathrm{RV}$-dependent coronary circulation is considered one of the most important factors in impaired $\mathrm{LV}$ function in patients with PA/IVS. Coronary perfusion is primarily derived from the aorta in the sinusoidal communication; however, if there are major stenoses of the coronary arteries, myocardial perfusion depends on both antegrade and retrograde pathways. The RV systolic pressure is usually much higher than the LV systolic pressure in PA/IVS. In RVdependent coronary circulation oxygen delivery to the myocardium more or less depends on the RV cavity $\mathrm{So}_{2}$. These coronary abnormalities cause ischemic damage to the LV myocardium.

Kado and associates ${ }^{13}$ reported on the LV performance of patients with PA/IVS after the Fontan procedure compared to those with tricuspid atresia. They concluded that RV-dependent coronary circulation was not always the main reason for $\mathrm{LV}$ functional disturbances in patients with PA/IVS. However, only 6 patients with RV-dependent coronary circulation were covered in their report. Akiba and Becker $^{14}$ found increased myocardial cell swelling and increased interfiber collagen content, reflecting chronic ischemia, in specimens from patients with PA/IVS and no coronary stenoses who had not undergone surgery. They did not demonstrate histologic abnormalities of the LV myocardium in RV-dependent coronary circulation. It therefore remains unclear to what extent $\mathrm{RV}$-dependent coronary circulation influences ischemic damage to the LV myocardium.

We hypothesized that BGS would improve the oxygenation of RV-dependent coronary circulation relative to 
systemic-pulmonary artery shunt. The reduction of systemic venous return to the right atrium after BGS could increase the $\mathrm{So}_{2}$ in the RV in the clinical setting, when the mixture of systemic and pulmonary venous blood is unchanged at the atrial level. In this study, the $\mathrm{So}_{2}$ in the RV cavity significantly increased after BGS $(P<.01)$. These results suggest that the BGS procedure improved the oxygen delivery to the myocardium in the $\mathrm{RV}$-dependent coronary circulation. On the other hand, the mixed $\mathrm{Vo}_{2}$ also significantly increased after BGS $(P<.01)$. Aortopulmonary shunt placement results in a volume load on the LV and a lowering of systemic diastolic pressure. The workload on the heart is increased while coronary perfusion is diminished in infants with a vulnerable myocardium. Thereafter, cardiac output decreased, resulting in low mixed $\mathrm{VO}_{2}$. The BGS reduces volume load and workload on the $\mathrm{LV}$ and increases cardiac output, resulting in high mixed $\mathrm{Vo}_{2}$. The systemic and pulmonary venous blood is mixed at the atrial level, and oxygenation of the myocardium depends in part on the $\mathrm{So}_{2}$ of the $\mathrm{RV}$, which is nearly equal to the saturation of atrial blood in the RV-dependent coronary circulation. Among 7 patients, only 2 underwent an atrial septectomy as a concomitant procedure with BGS. In 5 other cases, there were no differences in the atrial communication before and after BGS. However, the results reveal that both the reduction of systemic venous return to the right atrium and the elevation of mixed $\mathrm{VO}_{2}$ affected the $\mathrm{So}_{2}$ of the $\mathrm{RV}$ after BGS.

In this study, the BGS was performed at an average of 22 months (range 11-44 months). The interval between MBTS and BGS was 16.5 months. Early BGS has been performed for the palliation single-ventricle heart, to reduce the volume load of the single ventricle. ${ }^{15}$ Early BGS should also be recommended to prevent the progression of an excessive workload on the $\mathrm{LV}$ and myocardial ischemia in patients with PA/IVS with RV-dependent coronary circulation.

\section{References}

1. Lightfoot NE, Coles JG, Dasmahapatra HK, Williams WG, Chin K, Trusler GA, et al. Analysis of survival in patients with pulmonary atresia and intact ventricular septum treated surgically. Int J Cardiol. 1989;24:159-64.

2. Coles JG, Freedom RM, Lightfoot NE, Dasmahapatra HK, Williams WG, Trusler GA, et al. Long-term results in neonates with pulmonary atresia and intact ventricular septum. Ann Thorac Surg. 1989;47: 213-7.

3. Rychik J, Levy H, Gaynor JW, DeCampli WM, Spray TL. Outcome after operations for pulmonary atresia with intact ventricular septum. J Thorac Cardiovasc Surg. 1998;116:924-31.

4. Jahangiri M, Zurakowski D, Bichell D, Mayer JE, del Nido PJ, Jonas RA. Improved results with selective management in pulmonary atresia with intact ventricular septum. J Thorac Cardiovasc Surg. 1999;118: 1046-55.

5. Zuberbuhler JR, Anderson RH. Morphological variations in pulmonary atresia with intact ventricular septum. Br Heart J. 1979;41:281-8.

6. Miyaji K, Shimada M, Sekiguchi A, Ishizawa A, Isoda T, Tsunemoto M. Pulmonary atresia with intact ventricular septum: long-term results of "one and a half ventricular repair." Ann Thorac Surg. 1995;60: $1762-4$.

7. Kern MJ, King SB 3rd, Douglas JS Jr, Franch RH. Cardiac catheterization, and coronary blood flow and pressure measurement: In: Fuster V, Alexander RW, O'Rourke RA, editors. The heart, vol 1. 11th ed. New York: McGraw-Hill; 2004. p. 517.

8. Bull C, de Leval MR, Mercanti C, Macartney FJ, Anderson RH. Pulmonary atresia and intact ventricular septum: a revised classification. Circulation. 1982;66:266-72.

9. Daubeney PE, Delany DJ, Anderson RH, Sandor GG, Slavik Z, Keeton BR, et al. Pulmonary atresia with intact ventricular septum: range of morphology in a population-based study. $J$ Am Coll Cardiol. 2002;39:1670-9.

10. Giglia TM, Mandell VS, Connor AR, Mayer JE, Lock JE. Diagnosis and management of right ventricle-dependent coronary circulation in pulmonary atresia with intact ventricular septum. Circulation. 1992; 86:1516-28.

11. Mair DD, Julsrud PR, Puga FJ, Danielson GK. The Fontan procedure for pulmonary atresia with intact ventricular septum: operative and late results. J Am Coll Cardiol. 1997;29:1359-64.

12. Najm HK, Williams WG, Coles JG, Rebeyka IM, Freedom RM. Pulmonary atresia with intact ventricular septum: results of the Fontan procedure. Ann Thorac Surg. 1997;63:669-75.

13. Tanoue Y, Kado H, Maeda T, Shiokawa Y, Fusazaki N, Ishikawa S. Left ventricular performance of pulmonary atresia with intact ventricular septum after right heart bypass surgery. $J$ Thorac Cardiovasc Surg. 2004;128:710-7.

14. Akiba T, Becker AE. Disease of the left ventricle in pulmonary atresia with intact ventricular septum. The limiting factor for long-lasting successful surgical intervention? J Thorac Cardiovasc Surg. 1994; 108:1-8.

15. Reddy VM, McElhinney DB, Moore P, Haas GS, Hanley FL. Outcomes after bidirectional cavopulmonary shunt in infants less than 6 months old. J Am Coll Cardiol. 1997;29:1365-70. 